\title{
Los catálogos humorísticos de las Exposiciones Nacionales de Bellas Artes en el último tercio del siglo $\mathrm{XIX}^{1}$
}

\author{
Moisés Bazán de Huerta \\ Universidad de Extremadura
}

RESUMEN:

Las Exposiciones Nacionales de Bellas Artes son un factor relevante para valorar el arte español contemporáneo. Inauguradas en 1856, durante más de un siglo fueron la principal vía promocional y su celebración se convirtió en un evento no solo artístico, sino también social. Se publicaba un Catálogo Oficial, que identificaba títulos y autores. Pero generaban también guías y ediciones paralelas, además de un gran aparato crítico en prensa.

Nos ocupamos en concreto de los catálogos humorísticos que parodiaban en versos satíricos el contenido de las Exposiciones. Es una fuente poco conocida y singular, escrita para servir de guía al espectador mientras visitaba la muestra. Sus autores fueron escritores con afianzada trayectoria y también críticos de arte, que aunaban destreza literaria, ingenio y humor. El artículo analiza estas fuentes y recoge amenos ejemplos que ofrecen una alternativa a la crítica de arte en el último tercio del XIX.

\section{ABSTRACT:}

National Fine Arts Exhibitions are a factor of great importance to appreciate contemporary Spanish art. Open in 1856, these exhibitions were its main promotional way for more tan a century and their celebration became not only artistic events, but also social. An Official Catalogue was published, identifying titles and authors. But they also created guides and parallel editions, as well as a great number of press reviews.

We deal specifically with humorous catalogues which spoofed in satirical verses these exhibitions contents. It is an unique and little known source, written to serve as a visitor guide while visiting the exhibition. Authors were well-stablished writers and also art critics, who combined great literary skills, inventiveness and sense of humour. The article discusses these sources and provides enjoyable examples which offer an alternative way to art criticism in the last third of the 19th century.

\section{PALABRAS CLAVE:}

Exposiciones Nacionales, catálogo, crítica de arte, humor, arte español.

\section{KEYWORDS:}

National Exhibitions, Catalogue, Art Criticism, Humour, Spanish Art.

Este texto ha contado con Ayuda del S.E.C.T.I. (Sistema Extremeño de Ciencia y Tecnología e Innovación) al Grupo de Investigación de la Junta de Extremadura ARPACUR “Arte y Patrimonio Moderno y Contemporáneo (HUM 012)". 
Las Exposiciones Nacionales de Bellas Artes constituyen uno de los factores más relevantes para valorar la trayectoria del arte español contemporáneo. Fueron inauguradas en 1856, bajo la referencia de los Salons parisinos, con el fin de que el Estado propiciara el estímulo de las artes y fomentara la competencia entre los creadores. Con una periodicidad bianual, mantenida en el tiempo sin demasiadas excepciones, se acabó convirtiendo en la principal vía para la promoción artística y obtener una consagración en dicho panorama. El éxito de la iniciativa y la falta de alternativas permitieron que se prolongaran hasta 1968, momento en que las circunstancias culturales realmente habían cambiado, si bien el modelo hacía tiempo que se había quedado obsoleto. En cualquier caso, durante el periodo que contemplamos fueron el evento expositivo español más destacado y para el mismo los artistas preparaban sus mejores obras.

Para el conocimiento de estos certámenes es clave el libro de Bernardino de Pantorba ${ }^{1}$, una extensa base de datos que recopila todos los nombres de los participantes y premiados, estos últimos con breves datos biográficos, y un valioso apéndice fotográfico. El trabajo incluye también una amplia introducción y valoraciones críticas del autor, muy personalizadas. Al mismo hay que añadir la Tesis Doctoral de Jesús Gutiérrez Burón, Exposiciones Nacionales de pintura en España en el siglo XIX, defendida en 1997 y plasmada en numerosos artículos temáticos. Y, muy completos y actualizados, los tres tomos firmados por Lola Caparrós que analizan el desarrollo de estos certámenes durante el siglo $\mathrm{XX}^{2}$.

Las Exposiciones, llamadas en el XIX tanto Nacionales como Generales, contaban con un Catálogo Oficial, que recoge identificadas y numeradas todas las obras y sus autores. Tras consignar primero los miembros de los Jurados, el listado se organiza por secciones (Pintura, Escultura, Arquitectura y Arte decorativo). Dentro de cada una los artistas se relacionan alfabéticamente, aportando unos mínimos da-

PANTORBA, Bernardino de (José López Jiménez), Historia y crítica de las Exposiciones Nacionales de Bellas Artes celebradas en España, García-Rama, Madrid, 1980 (tuvo una primera edición en 1948).

2 Citamos el primero: CAPARRÓS MASEGOSA, Lola, Historia y crítica de las Exposiciones Nacionales de Bellas Artes (1901-1915), Universidades de Granada y Santiago de Compostela, Granada, 2014. tos sobre su origen, si son discípulos de algún maestro o Escuela y la obtención previa de galardones, además de su residencia. En las obras, bajo el título, figuran también sus medidas. En los catálogos más tempranos ${ }^{3}$ aparece además a menudo la descripción del asunto que las inspira. La numeración de las piezas obviamente no tenía correlación con la ubicación física en las salas, para lo que primaban otros criterios. La presencia mayoritaria de la pintura es abrumadora respecto a las otras secciones y no deja dudas sobre la preeminencia de este campo artístico ${ }^{4}$.

Paralelamente a los catálogos oficiales se editaron también otros de carácter crítico, con distintos medios, desde los más selectivos de Ibáñez y Comas al muy extenso y cuidado de Francisco de Alcántara, con un profuso aporte fotográfico ${ }^{5}$. Y además surgen breves guías, financiadas con publicidad, que permitían una rápida identificación de las obras ${ }^{6}$. Por supuesto, la relevancia de las Exposiciones Nacionales generaba al tiempo numerosas reseñas en revistas de actualidad y diarios, configurando uno de los aparatos críticos más importantes de la época, apto para amplios sectores de la opinión pública.

Pero su alcance las convirtió también en un acontecimiento social, y a su reclamo asistía la clase burguesa madrileña, incluso familias enteras, llegando a instituirse el "día de moda",

Véase Catálogo de la Exposición Nacional de Bellas Artes de 1866, Colegio de sordomudos y de ciegos, Madrid, 1867.

4 A título de ejemplo, el catálogo oficial de 1897, sobre un total de 1.608 obras, incluye: 1.166 pinturas, 143 esculturas, 16 proyectos arquitectónicos y 240 piezas decorativas, más un apéndice de 43 en su mayoría del último bloque. Catálogo de la Exposición General de Bellas Artes 1897. Edición Oficial, Celestino Apaolaza Impresor, Madrid, 1897. En 1899 serían respectivamente 907, 99, 13 y 171. Catálogo de la Exposición General de Bellas Artes 1899. Edición Oficial, Hijos de J. A. García, Madrid, 1899.

5 IBÁÑEZ ABELLÁN, R., Catálogo crítico explicativo de la Exposición Nacional de Bellas Artes de 1881, Montoya y Cía., Madrid, 1881. COMAS Y BLANCO, Augusto, La Exposición Nacional de Bellas Artes de Madrid 1890, Sucesores de Rivadeneyra, Madrid, 1890 (16 ilustraciones). ALCÁNTARA, Francisco, La Exposición Nacional de Bellas Artes 1897, Centro Editorial Artístico, Madrid, 1897, con casi 300 páginas y 177 fotografías entre obras y retratos de los artistas.

6 Exposición General de Bellas Artes en 1899. Catálogo numerado. Guía del visitante. Reseña exacta de obras expuestas, autores de las mismas y número de orden correspondiente, Imprenta de El Enano, Madrid, 1899 (20 páginas). 
en que se lucian las mejores galas. Durante el tiempo de exposición, normalmente entre mayo y junio, centraban por tanto la actividad cultural española, pues sus resultados alcanzaban proyección nacional.

En todo este contexto se sitúa nuestro ámbito de estudio y la hipótesis de trabajo. Nos centramos en la publicación paralela de catálogos humorísticos que parodiaban de forma satírica el contenido de las Exposiciones ${ }^{7}$. Constituyen un medio singular, no demasiado conocido y que pronto valoraremos en su verdadero alcance, aunque conviene apuntar ya algunas de sus particularidades. La primera es su carácter funcional, ya que se conciben para ser usados durante la visita, a modo de guía jocosa, si bien pueden disfrutarse también al margen del evento. Sus autores son escritores con afianzada trayectoria literaria, muchos de ellos habituales en la prensa de la época, y no solo la humorística. Algunos se definen como legos en materia artística, aunque se arrogan el derecho a poder expresar su opinión, al igual que realiza el gran público. Pero también hay críticos de arte, como Segovia Rocaberti, que ejercen en paralelo la crítica seria y denotan buenos conocimientos del medio y el lenguaje plástico. Con todo, la actitud general es honesta en cuanto a sus pretensiones, considerándolo un divertimento sin excesivas ínfulas que, eso sí, satisfacía las demandas del público.

En cualquier caso no es un género fácil. Requiere aunar ingenio, gracia, capacidad de observación, espíritu crítico, ciertos conocimientos artísticos, recursos literarios y maestría para versificar, compendio cuyo equilibrio puede no estar siempre a la misma altura. El resultado por tanto es desigual, pero ofrece en general un buen nivel, entretenimiento asegurado y momentos muy inspirados. Somos conscientes de que no es una fuente capital para la historiografía artística, pero sí un complemento que ofrece una visión novedosa y alternativa digna de consideración.

En lo personal, este es un proyecto largamente acariciado. Llevamos adquiriendo ejemplares desde los años noventa, aunque el número inicial disponible era aún exiguo. Otros

\footnotetext{
Podemos encontrar sus antecedentes en los Salones Caricaturescos que aparecieron en Francia en la segunda mitad del siglo XIX. CABANNE, Thierry, Les Salons Caricaturaux, Musée D’Orsay-Réunion des Musées Nationaux, París, 1990.
}

fueron consultados en Bibliotecas y Hemerotecas, y en los últimos años, la digitalización de fondos de algunas instituciones ha permitido obtener un número suficientemente representativo para abordar el estudio con solvencia. No descartamos, con todo, que puedan localizarse nuevas referencias.

Metodológicamente nuestra investigación presenta algunas peculiaridades. La afrontamos desde la perspectiva de la Historia del Arte, pero las fuentes pertenecen más al terreno literario que al visual. En gran medida porque los catálogos humorísticos en su mayor parte no están ilustrados, y tampoco los oficiales, salvo algunas ediciones paralelas citadas. Y es entendible, ya que abordar en su momento una publicación ilustrada hubiera causado problemas en la selección de obras y encarecido notablemente el proceso. Por su parte, los catálogos humorísticos son publicaciones divulgativas y económicas, cuyo coste, de incluir imágenes, se hubiera disparado perjudicando su salida comercial. El caso es que ambas situaciones dificultan la comparación entre las obras plásticas originales y los comentarios que se vierten sobre ellas, que sería siempre lo más eficaz. Es tan ingente el número de piezas expuestas que en la mayoría de ocasiones hemos de intuir solo el proceso seguido. A pesar de todo, pueden rastrearse suficientes ejemplos a partir de las fotografías de las obras premiadas y la información que se ofrece en diferentes revistas de la época, más revisiones historiográficas posteriores ${ }^{8}$.

Conviene matizar que un similar enfoque se puede afrontar desde el chiste gráfico, con resultados incluso más directos y eficaces. De hecho, bastantes revistas humorísticas de la época dedicaban también sus páginas a parodiar con dibujos las pinturas y esculturas expuestas en las Nacionales, junto a otras manifestaciones artísticas $^{9}$. Pero es un campo paralelo susceptible de ser tratado en otro momento.

${ }^{8}$ Ver REYERO, Carlos, Escultura, Museo y Estado en la España del siglo XIX, Fundación Eduardo Capa, Alicante, 2001.

9 Véanse entre otros BAZÁN DE HUERTA, Moisés, "El monumento público visto por el humor gráfico", en Norba-Arte, no 35, Cáceres, 2005, pp. 303-330. CAPARRÓS MASEGOSA, Lola y GAMONAL TORRES, Miguel Ángel, "Gedeón en las Exposiciones Nacionales de Bellas Artes (1897-1912). Las críticas de arte y caricatura política en la España de la Restauración”, en Cuadernos de Arte de la Universidad de Granada, $\mathrm{n}^{\circ}$ 41, 2010, pp. 249-268. REYERO, Carlos, "Monumentos españoles en caricatura, 1860-1920", en Laboratorio de Arte, n 29, 
Pasando ya a concretar la estructura de estos catálogos humorísticos, conviene señalar que suelen comenzar con un prólogo en el que se contextualiza la iniciativa, relatando el recorrido hacia la Exposición o las peripecias sufridas para la elaboración de los mismos. Tras ese inicio se reseña la selección de piezas, para concluir con un epílogo jocoso que puede dejar abierta una próxima cita, aunque no siempre ésta se produce. Para dar fluidez a la lectura, lo más frecuente es el uso del arte menor: pareados, cuartetas, redondillas, aunque en realidad encontramos una gran libertad compositiva, alternándose todo tipo de estrofas y también la prosa. Las peculiaridades por autores las iremos conociendo en cada caso; pero en general domina el buen tono, sin descalificaciones excesivamente duras, aunque se cuestione con frecuencia la calidad de las obras o la capacidad del artista, algo que imaginamos no sentaría muy bien a los pintores o escultores citados, que ven de un plumazo ridiculizado todo su esfuerzo. En buena lógica, en las referencias aparecen todos los temas o géneros habituales en estas exposiciones: pintura de historia, a veces religiosa, retrato, bodegón, paisaje, costumbrismo y también el miserabilismo de tintes dramáticos tan presente en las muestras finiseculares.

Estamos por tanto ante un género propio, cuya peculiaridad era ser usado como guía para visitar la Exposición. Cabe imaginar a parte de los espectadores dotados de su pequeño catálogo para esbozar una sonrisa al leer frente al cuadro o la escultura de turno los chascarrillos de los autores. Son muchos los ejemplos que verifican este objetivo, al contener indicaciones precisas para desplazarse por las salas.

En 1871, el periodista y dramaturgo zamorano Miguel Ramos Carrión (1848-1915) se alía con el también poeta y escritor José Campo Arana (Madrid, 1847-1884) para configurar un primer catálogo sobre la Exposición Nacional ${ }^{10}$, abriendo una serie de colaboraciones posteriores en forma de comedias, zarzuelas y sainetes. En el prólogo se presentan como aficionados

Sevilla, 2017, pp. 589-602. GUIJARRO ALONSO, José Luis, Cuidado con la pintura. Caricaturas del arte en tiempo de vanguardias: Madrid, 1909-1925, Eutelequia, Madrid, 2012.

10 RAMOS CARRIÓN, Miguel y CAMPO ARANA, José, Revista Cómica de la Exposición de Bellas Artes de 1871, Imprenta de la Biblioteca de Instrucción y Recreo, Madrid, 1871 (84 páginas). http://bibliotecadigital.jcyl.es/ es/consulta/registro. $c m d$ ?id= 5849 . que se hacen eco de la "impresión primera", al igual que la opinión pública. En el texto no se identifica cada autoría, y no se aprecian claras diferencias, por lo que hay que entenderlo como obra cooperativa con reparto equitativo de tareas.

Como será habitual, el recorrido se organiza por salas, guiando al lector durante la visita, separando los bloques de pintura y escultura. Se caracterizan por una versificación breve, ágil, que en general oscila entre los dos y cuatro versos. Sus observaciones son prioritariamente formales, señalando defectos por composición, deformaciones, alteración de la escala o calidades texturales. Unos primeros ejemplos:

Villaverde y Castera, Un niño dormido: "Niño de varios colores;/ fondo un queso, mucha yerba,/ y tiene un gran desarrollo,/ sobre todo en una oreja". Perate, Puerta judiciaria de la Alhambra: "Trabajo en chocolate./ No tiene pero/ para el escaparate/ de un confitero".

Tampoco la escultura se libra. Sobre el Joven griego de Almeida, comentan: "Aunque acabó la vendimia,/ ¿no ha quedado en toda España/ para cubrir a este joven/ alguna hojita de parra?"; y un busto de Alcoverro es "un Rossini de Zarzuela/ metido en una cazuela."

Se detecta por último un cuestionamiento del non finito, que reaparecerá en posteriores revisiones. Así, ante la polémica Muerte de $\mathrm{Lu}$ crecia de Eduardo Rosales, los autores recriminan: "Cansado tal vez de usar/ el pincel que tanto honró,/ este boceto pintó/ con la brocha de afeitar."

Dos catálogos humorísticos glosan el certamen de 1876. El escritor y abogado José del Castillo y Soriano (1849-1928) ${ }^{11}$ lo presenta de forma original bajo el título Dos horas de exposición $^{12}$, un librito de 48 páginas que es una excepción en el conjunto, pues no incluye división por salas, ni siquiera el nombre de los artistas, y se centra solo en la pintura. Predominan las estrofas en forma de copla, con octosílabos de rima asonante en los pares, aunque encontramos también otras fórmulas y algún retruécano: "Un cesto muy diminuto/ y una

\footnotetext{
${ }_{11}$ Ver http://dbe.rah.es/biografias/72730/jose-del-castillo-y-soriano.

12 CASTILLO Y SORIANO, Dos horas de exposición. Apuntes cómicos de la de Pinturas de 1876, Imprenta de Manuel Hernández, Madrid, 1876 (48 páginas). http:// www.memoriademadrid.es/buscador.php?accion=VerFichactid=29480\&tnum_id=79ctnum_total=88.
} 
porción de racimos,/ no es canastillo con uvas,/ es uvas con canastillo".

$\mathrm{Su}$ autor se define como un curioso, "que no es pintor ni es crítico, como tendrán ocasión de observar más adelante los críticos y los pintores". Puede mostrarse admirativo, valorando el realismo de los paisajes de Haes Canal de Mancorbo y Costa de Lequeitio: "-Paisajes bellos, divinos;/ esto sí que es natural.../ - ¿De quién es?/ -De Carlos Haes./ -Pues no me diga usted más". Pero en general su tono es duro, y a veces faltón, como ante el Retrato de $S$. $M$. el Rey, de Juan Alaminos, que juzga: "El asunto es inviolable;/ la ejecución criminal;/ el delito cometido/ es de lesa-majestad". Prisión del trovador: "Solo veo pretensiones/ al contemplar este cuadro;/ de todo lo que contiene/ lo más bonito es el marco". 0 el Retrato de una señorita, de Luis Franco, definido como "Polvos de arroz, almidón,/ transparencia de papel;/ el autor mojó el pincel/ en espuma de jabón".

Incluso se permite exhortar directamente al artista, y sobre los siete Cuadritos del Sr. Pérez Rubio, señala: "Verdad, corrección, vigor;/ fecundo en buenas ideas,/ icómo lamento que seas/ un artista al por menor!/ Manía tan extremada/ hará que pintes, sin gloria,/ toda la moderna historia/ en cuadritos de a pulgada". 0 cuestiona algunas audacias, recomendando ante El examen: "Muñoz Degrain, te aconsejo/ que pintes, no hagas labor/ de exposición de labores,/ que esa no es tu profesión./ No filigranes tus obras/ con cristales de color,/ muy buenos para agitarlos/ en un tubo de cartón".

Y para no abundar en más ejemplos, reproducimos finalmente el irónico epílogo: "Al ver la noche venir/ del Pabellón al salir,/ cuando ya iban a cerrar/ quise otras obras mirar,/ quise volverme a reír./ Más noté que embellecían/ conforme la luz perdían,/ y al verlos de sombra llenos/ de lejos... me parecían/ todos los cuadros muy buenos./ ¡Cubra del arte el local/ la noche con su capuz.../ la Exposición nacional/ no debe tener rival,/ vista de noche y sin luz!".

El otro catálogo que glosa la Exposición de 1876 está firmado por los comediógrafos y humoristas Salvador María Granés (1840-1911) y José Mariano Vallejo (1843-1911) ${ }^{13}$; amplio, con 112 páginas, identifica números, títulos $\mathrm{y}$

13 Catálogo cómico-crítico de la Exposición de Bellas Artes de 1876 escrito en verso y prosa por los Sres. Granés y Vallejo, Imprenta de F. Iglesias y P. García, Madrid, 1876 (112 páginas). autores y se ocupa de todas las secciones. Confiesan ignorancia e impericia en materia pictórica, y "si no es buena como revista cómica, te ofrece, por lo menos, la ventaja de ser un catálogo de la Exposición, ordenado y dispuesto por salas, y menos molesto, por tanto, que el confeccionado no sabemos por quién y que se vende a la puerta del edificio que juntos vamos a visitar". De hecho, una de sus singularidades es dar paso versificado a cada una de las salas: "Si aún tienes valor, lector/ (que es tener mucho valor/ después de sufrir tal tunda),/ tose, límpiate el sudor/ y entra en la... Sala Segunda".

El catálogo es también una opción interesante al tratar a veces las mismas obras que Castillo, aunque su enfoque es más variado y presenta un mejor nivel literario. En tan amplio repertorio encontramos arte mayor (cuartetos y serventesios), y otras estrofas y figuras (retruécanos). Pero su especialidad son las quintillas, que proliferan con los más variados temas. Ignacio Suárez Llanos, Retrato de la Señora doña T. Z. de Ll.: "Del parecido no trato;/ mas sí diré pese a siete/ que está ¡horrible desacato!/ retratada en su retrete/ la señora del retrato". Antonio Tomasich, Retratos en miniatura: "No están mal; pero aunque yerre/ en ello, se me figura/ que el invento de Daguerre/ hará que al fin se destierre/ del mundo la miniatura".

Algunos comentarios son especialmente severos: José Nin y Tudó: “Era la niña inexperta/ y corrió a la muerte cierta/ de tu paleta nociva;/ se puso en tus manos viva/ y la has retratado muerta". Nicasio Serret, Prisión de la última reina de Mallorca: "Trajes de guardarropía/ son los del rey y el infante,/ y es el de la reina aquella/ de mármol por lo implegable./ Este cuadro, a no dudar,/ hará reír a los sastres. (P. S. Los compradores de terrenos por pies cuadrados deben elegir como unidad de medida el pie soberano pintado por el Sr. Serret, y que a decir verdad es todo un soberano pie)"14. (Fig. 1)

Y una vez más, no pasan desapercibidos los apuntes impresionistas: "El dibujo es descuidado/ y tan tenue el colorido,/ que más que recién pintado/ parece recién barrido/ o mejor, recién borrado" (Antonio Pérez Rubio, Intriga contra D. Francisco de Quevedo). 0, como se aplica al cuadro de Cristóbal Ferriz: "No son las Inmediaciones/de Aranjuez lo que me apura,/ sino

\footnotetext{
14 Recordemos que el cuadro de Serret obtuvo Segunda Medalla, no habiéndose concedido Primeras en este certamen.
} 


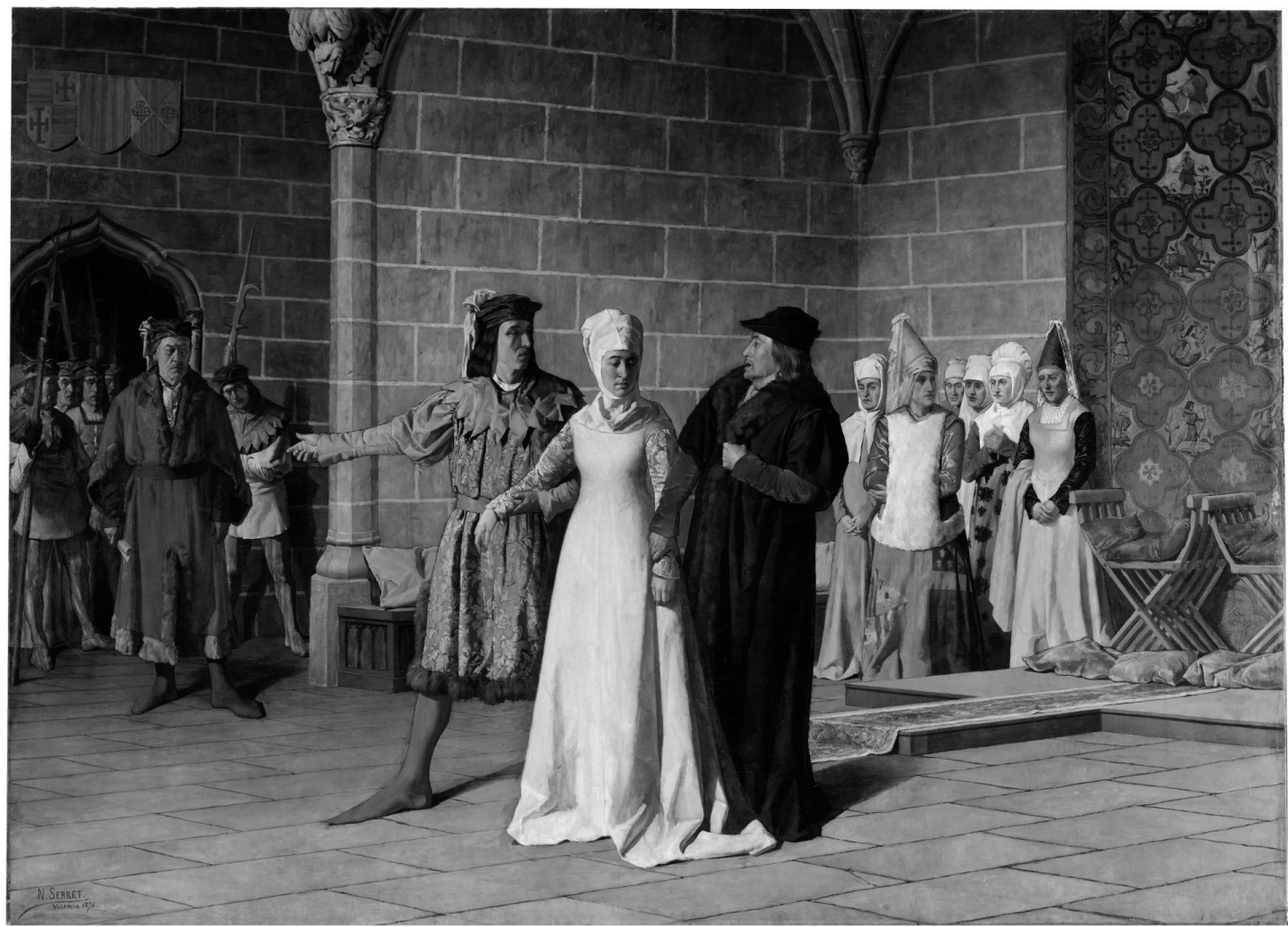

Fig. 1. Nicasio Serret. Prisión de la última reina de Mallorca. Exposición Nacional de Bellas Artes de 1876. Museo del Prado-Palacio del Senado.

el montón de pintura/ que has hecho a chafarrinones".

En la edición celebrada en 1881, José Mariano Vallejo ${ }^{15}$ cambia de pareja literaria, para abordar un nuevo catálogo junto a Francisco Serrano de la Pedrosa, redactor en diarios como La correspondencia ilustrada o El globo, y colaborador habitual de Madrid Cómico. De forma avispada declaran que no son críticos pictóricos, para desagraviar a "aquellos pintores cuyas obras no hayan merecido nuestra indulgencia, puesto que si nuestra censura es desautorizada, no debe dolerles" ${ }^{16}$. La premisa es que "hay pinceles de los que cuelga siempre una $d$, y buscando el efecto, queda el $d e-$ fecto sobre el lienzo". Su misión es captarlo y asumen que quizás en algún momento se les haya ido la mano. Puede ser cierto, ya que hay bastantes descalificaciones genéricas, que tiran de repertorio, pero son lógicas en cuanto que la crítica negativa vende más que la positiva y

15 Cabe destacar la contribución paralela de este autor al proceso de enseñanza de la lectura en la época.

16 VALLEJO, José Mariano y SERRANO DE LA PEDROSA, Francisco, Catálogo cómico-crítico de la Exposición de Bellas Artes de 1881, Tip. Correspondencia Ilustrada, Madrid, 1881 (160 páginas). llega mejor a un público ávido de bromas para comentar.

El estilo es ágil, con estrofas menores, normalmente coplas, cuartetas o redondillas, pero sigue una estructura bastante uniforme, incluso monótona dada la amplitud del catálogo. Es de hecho el más extenso de los consultados, con 160 páginas, en el que Vallejo mantiene la pauta de guiar con versos el acceso a cada Sala y el recorrido interno. En la contracubierta los autores recuerdan que puede adquirirse a peseta a la entrada de la Exposición, en la sede administrativa de La Correspondencia Ilustrada y en numerosas librerías, dando cuenta de su amplia difusión.

En el certamen hubo por invitación bastante presencia portuguesa, que recibe severas criticas, aunque no en mayor medida que los autores hispanos. Silvio Fernández: "Torquemada: inquisidor/ que tostaba al mundo entero;/ y efectivamente, el cuadro/ está pidiendo ir al fuego". Luis Cuervas-Mons, Montañas de Reinosa: "Hay un árbol que parece/ que está bailando el can-can,/ y esto es lo mejor del cuadro;/ ¿qué tal será lo demás?”.

Por géneros, precisamente el paisaje no suele salir bien parado. Emilio Perich, Alrededores 
de Madrid: "Sabía que el Manzanares/ era de caudal escaso;/ pero nadie me había dicho/ que fuera un río de asfalto". Joaquín Sorolla, $M a-$ rina: "El agua desnivelada,/ sumergido el barracón.../ esto querrá ser marina,/ pero es una inundación”. Tampoco les va bien a los bodegones, con cierta inquina ante las propuestas del extremeño Felipe Checa; o al costumbrismo: Félix Bricio, La oración: "Desde muy niño entendí/ que era buena la oración,/ pero cambié de opinión/ en cuanto tu cuadro vi". Joaquín de Carpi, El cántaro no se ha roto: "Mantecosa es por mi vida/ esta moza cari-llena,/ y hasta el cántaro parece/ que come también manteca". Más tibios son ante los retratos, identificados solo con iniciales y que a menudo no juzgan al no poder compararlos con el modelo, aunque también haya ejemplos mordaces: Germán Valdecara, Retrato de la señora doña P. V.: "Tiene una cara de duelo/ que no cabe pedir más,/ y por el gesto parece/ que se va a echar a llorar". En la pintura de historia, aunque lo comentan, quizá perdieron la oportunidad de sacar más partido por su truculencia al polémico cuadro La leyenda del Rey Monje de José Casado del Alisal, si bien no faltan otras irónicas referencias.

Con todo, siguen generando buenas estrofas los juegos de palabras y retruécanos con los títulos y nombres de los artistas. Así, las pruebas litográficas de Martínez Ginesta se califican de Miscelánea indigesta. Vista del Generalife (Granada), de Manuel Castaño: "Pintando el Generalife,/ que es lo mejor de Granada,/ me parece que Castaño/ nos ha dado la castaña". Vicente Izquierdo, Ruinas del castillo de Hendaya y vista de la playa: "El mismo pintor ha hecho/ la aleluya de su cuadro/ y aún lo hace mucho mejor,/ escribiendo que pintando". Joaquina Serrano, Vista del Observatorio de Madrid: "Tu observatorio, observado/ debe ser con microscopio;/ pues si no, no es observable/ tan pequeño observatorio". Joaquín María Herrer, El Emperador Carlos $V$ recibiendo el Viático en Yuste: "Ahí se muere Quirlos Canto;/ me equivoqué, Carlos Quinto;/ lo que está tan mal pintado/ no puede estar bien escrito".

Por último cabe comentar que hemos detectado algunos refritos respecto al catálogo de 1876, recuperando estrofas que ahora se aplican a otros cuadros del mismo o distinto autor.

En 1884, tras su experiencia en el anterior certamen, Serrano de la Pedrosa asume el pro- yecto en solitario ${ }^{17}$. Como ocurrente novedad, abre diciendo: "El prólogo, lector, es enfadoso;/ pero ya que es forzoso,/ lo escribiré muy breve y compendioso", para poner en las tres páginas siguientes la palabra "PRÓ/LO/GO" con grandes letras decorativas. Incorpora además un útil plano de la Exposición que ayuda a situarse en la misma.

En las reseñas hay mayor presencia de pareados, junto a estrofas varias de cuatro versos y oportunos ripios, más algún inserto serio. El tono general es amable, aunque sin obviar las consabidas descalificaciones y abundando en adjetivos como malo. Junto a lugares comunes, a estas alturas ya conocidos, el texto es entretenido y suficientemente variado. Entre sus notas distintivas está la alusión a políticos o personajes de la época, una notable presencia de pintoras y la encendida defensa del cuadro Spoliarium de Juan Luna, que acabaría siendo Primera Medalla.

El espacio disponible no nos permite seleccionar una amplia lista de ejemplos, pero valgan estas muestras entre las más negativas: Ardanaz, Naturaleza muerta: "Esta duda me encocora:/ ¿pongo muerta o matadora?”. Fernández Carpio, iNos hemos lucido!: "Está satisfecho el arte,/ porque a confesión de parte...". Amell, Venta al anticuario: "Anticuado es el asunto/ y anticuadas las levitas,/ y anticuada la manera.../ jay qué cosa tan antigua!". Juan Espina: "Entorna, lector, los ojos/ y empezarás a ver algo;/ ciérralos completamente.../ y verás qué hermoso cuadro".

En la Exposición Nacional de 1887 contamos de nuevo con dos catálogos que permiten hacer una evaluación paralela. Juan P. de Zabala firma el primero, con 136 páginas y el anuncio de incluir versificados todos los cuadros de la muestra, aunque en realidad la mayoría solo aparezcan titulados ${ }^{18}$. Se edita con la Exposición comenzada y los premios ya concedidos, que figuran al final del mismo. No

17 SERRANO DE LA PEDROSA, Francisco, Catálogo cómico-crítico de la Exposición de Bellas Artes de 1884, Tipografía Hispano-Americana, Madrid, 1884 (112 páginas).

18 ZABALA, Juan P. de, iAcabaditos de premiar! Catálogo completo de la Exposición de Bellas Artes con la crítica en verso de todos los cuadros, Tipografía de Manuel Ginés, Madrid, 1887 (138 páginas). Recoge 853 pinturas, dibujos y grabados, 72 esculturas y 16 proyectos arquitectónicos. http://memoriademadrid.es/buscador. php? accion=VerFichattid=29474\&num_id=8\&tnum total $=152$ 
es por tanto en este caso una guía por salas; sigue el modelo oficial y los artistas se relacionan por orden alfabético y numeración consecutiva.

El proyecto no alcanza el nivel de otros, pues sus apreciaciones abusan de los banales o inconcretos bonito, bueno, malo, feo, me gusta o no me gusta ${ }^{19}$. En el largo prólogo, un tanto farragoso, elogia a Sorolla y cuestiona al Jurado, algo que reaparece al valorar algunas de las pinturas. Juan Poveda, Muerte del Príncipe de Viana: "Poco vale, en verdad, lo que has pintado,/ aunque te asombre la opinión que emito:/ sé por demás que te premió el Jurado;/ pero el Jurado a mí... me importa un pito".

$Y$ en las reseñas, con frecuencia agrupadas, fluctúa entre algunos aplausos, como los dedicados a Ulpiano Checa o Virgilio Mattoni, y numerosos menoscabos, con algunas expresiones populares y a veces un tinte misógino. Clara Salazar, Retrato: "Usted se llama Clara,/ y como soy muy claro,/ con claridad le digo/ que eso es muy malo". Emilio Ordóñez, Castigo a una vestal: "Firme con ella, verdugo,/ y nada de compasión;/ dale una buena paliza,/ y después, otra... al pintor".

Enrique Segovia Rocaberti (Chinchón, 1853-Pinto, 1890) ejerció como periodista, poeta y dramaturgo, y estuvo también vinculado con la política, militando en el Partido Republicano. Colaboró en diarios humorísticos como El Coco o Madrid Cómico. En esta línea y para nuestros fines, hay que destacar la publicación del Catálogo Humorístico en verso de la Exposición Nacional de Bellas Artes de 1887, por la Librería de Fernando Fé. Es de todos los catálogos el que debió tener una tirada más amplia, pues aún se pueden conseguir ejemplares a la venta en portales especializados.

Fue publicitado en Madrid Cómico como "un derroche de gracia y de intención, además de revelar profundos conocimientos en la materia" $^{20}$. Y no van desencaminados, porque paralelamente el autor hace una amplia reseña de la Exposición entre los números 223 al 226 de la propia revista, ejerciendo de crítico serio como en cualquier otro medio de prensa, con criterio propio y fundamentados comentarios. La alternativa humorística es en este caso un

19 Un ejemplo revelador: Manuel Pícolo, Villalar: "Aunque tiene defectos/ y cosas malas,/ tiene cosas muy buenas, / bien dibujadas".

20 Madrid Cómico, año VII, n 223, 28 de mayo de 1887, p. 7. complemento de su competencia habitual como crítico de arte.

Demuestra un buen dominio en cuartetas, redondillas, coplas y quintillas, aunque encontramos también estrofas más extensas. Más amable que Zabala con las pintoras y en su tono general, reparte tanto elogios como críticas negativas (por las que en el Epílogo pide disculpas y ofrece desquite en que le silben cuando se produzca su próximo estreno). En los textos sobre pintura, sin faltarle humor e ironía, se percibe el mayor nivel y la cultura artística del autor, detectando similitudes, influencias e incluso plagios ${ }^{21}$.

Dado que es menos habitual, optamos por destacar sus apreciaciones sobre la escultura. De hecho, en la Introducción, camino de la muestra, aprovecha para comentar varios monumentos, como el del Marqués del Duero: “... pues está aquel Marqués tan aguerrido,/ más que fundido en bronce, confundido", o Isabel la Católica: “...los ediles que allí le han emplazado/ han dado prueba de ese mal sentido/ que al cargo concejil va siempre unido". Ante las obras expuestas, y salvo algún desliz, como confundir a Venancio Vallmitjana como padre de su en realidad hermano Agapito, los criterios son acertados, y a veces severos. Valora el extremo realismo de La tradición de Agustín Querol (Primera Medalla), cuyos brazos, señala, parecen fragmentos vaciados del natural. Cuestiona los bronces de José Arias como monigotes de San Isidro. Sobre la obra de Felipe Moratilla critica: “ ¿Se concibe en los tiempos actuales/ que exista un ciudadano/ tan pobre de ideales/ que venga con un Hermes pompeyano?". Ante Leónidas en el paso de las Termópilas, de Miguel Ángel Trilles, plantea: "Aunque aquí es de lo mejor,/ esa escultura no prueba/ que merezca el escultor/ llevar el nombre que lleva”. Y dado el gran número de piezas presentado por Justo de Gandarias, señala: "Por lo que veo, Gandarias,/ ha vaciado su taller”. (Fig. 2)

Antonio María Martínez Viergol (18721935), periodista que firmaba en el diario $\mathrm{El}$

\footnotetext{
Dos ejemplos de distinto signo. Enrique Estevan, África, 1860: "Hermosa composición/ en que todo está medido/ y tratado a perfección,/ tan llena de animación/ como rica en colorido./ De perspectiva brillante/ y dibujado a conciencia,/ nunca faltará delante/ de este cuadro interesante/ numerosa concurrencia”. Y ante los cuadros de Lino Casimiro Iborra: "Si quieres llegar a ser/ un excelente pintor,/ estudia sin tregua, Iborra,/ $y$ borra sin compasión".
} 


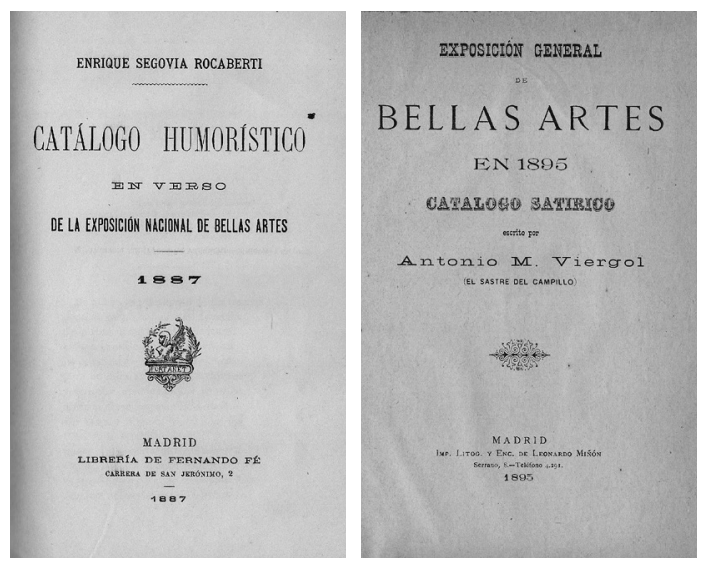

Fig. 2a y 2b. Catálogos humorísticos de las Exposiciones Nacionales de Bellas Artes de 1887 y 1895.

Liberal como El Sastre del Campillo, es autor de sendos catálogos satíricos en 1895 y 1897 , siendo por tanto obras de juventud ${ }^{22}$.

Afianzando la idea de que estos catálogos se conciben para guiarse por las abigarradas salas de la Exposición, con cuadros a varios niveles de altura, Viergol aclara en 1895 que ha ordenado y enumerado las obras por columnas de alto a bajo, buscando la comodidad del espectador y dando lugar a menos equivocaciones. Completa la información especificando en cada sala el orden a seguir.

En el de 1895 incluye todas las obras, pero en 1897 cambia el sistema y solo muestra los títulos de los ejemplos comentados. Aunque sigue organizando la distribución por salas, pone los números reales con que las obras aparecen en el catálogo oficial y la exposición, si bien falta una gran parte por las circunstancias precarias y rápidas en que se confeccionó la obra.

De hecho, sobre el proceso de elaboración de estos catálogos es Viergol quien nos ofrece la descripción más eficaz en 1897. En un largo prólogo en octosílabos cuenta las peripecias para poder tener el libro a tiempo, pues su gran reto es que esté a la venta el día de la inauguración, algo que no pudo conseguir en la exposición previa. Su principal objetivo es lograr en el Ministerio de Fomento el pase para entrar unos días antes y poder ver las piezas expuestas. Ofrece al tiempo valiosa información complementaria. Denuncia así el estado

22 VIERGOL, Antonio M., Exposición General de Bellas Artes en 1895 (y 1897). Catálogo satírico escrito por El Sastre del Campillo, Leonardo Miñón, Madrid, 1895 y 1897 (76 y 62 páginas). Dio continuidad a esta práctica en la siguiente centuria desde las páginas del diario $E l$ Liberal. de abandono del recinto, no revisado en dos años y teniendo que arreglarse a última hora ventanales y desperfectos, hasta que con un sinnúmero de operarios consiguen completar la cuelga en las últimas 48 horas. "Total, que hasta el día quince/ no empezaron a colgarse/ los cuadros, que, amontonados,/ dormían en una nave,/ inundándose de polvo/ y en peligro de rasgarse”. Identificándose como redactor de prensa, consigue un volante para entrar entre los días 21 y 24, colándose el día del barnizaje como ayudante de un marinista y redactando por las noches. "El veinticinco en la imprenta/ $\mathrm{y}$ el veintiséis ien la calle!/ Total: sin dormir seis dias,/ cuatrocientos mil percances,/ expuesto a volverme loco,/ y todo, ioh Dios! por dos reales".

El resultado se resiente del acelerado proceso. Es un tanto desigual, ya que muchos versos no son especialmente ingeniosos. Pero brilla también en composiciones muy inspiradas e incluye referencias cultas, trayectorias previas $\mathrm{y}$ es muy generoso con la longitud dedicada a determinadas piezas. Otra peculiaridad de sus textos es que alterna la prosa y el verso, e incluso introduce cortes bruscos para comentar algunas salas en tono serio, sin ninguna intención humorística, algo sorpresivo cuando se consulta el catálogo.

En 1895 cita 545 obras, de las que comenta un 60\%, y de dicho porcentaje un 46\% están en verso y el resto en prosa. En 1897, como apuntábamos, modifica el sistema, por cuanto solo incluye las piezas glosadas. Son ahora 209, de las que apenas un tercio aparece en verso ${ }^{23}$.

Son interesantes sendos prólogos, redactados desde una posición singular. En 1895 se declara partidario del socialismo político, pero reaccionario en el terreno artístico. Bajo el epígrafe "La exposición azul", critica esa "dictadura monocroma, falsísima y de gusto depravado, en virtud de un moderno impresionismo que trata de matar el arte clásico”. Sin embargo, sus reticencias con Santiago Rusiñol, que ejemplifica dicha tendencia, se verían modificadas solo dos años después, cuando señala que le está convenciendo y empieza a valorar sus virtudes. Por supuesto se ocupa también de las rivalida-

23 Un nuevo aspecto a comentar es que el escritor señala que tiene en preparación otros dos libros: uno sobre el Jurado y la Exposición, y dos tomos (Siluetas) bajo el título "Pintores y pintamonas. Escultores y escalpelinos”, aunque no nos consta su publicación. 
des por la obtención de medallas, apreciando unos y otros méritos, con una especial atención a Gonzalo Bilbao, Alberto Plá y Joaquín Sorolla.

La fluctuación estética de la crítica ha sido puesta de manifiesto en el ámbito de la escultura ${ }^{24}$; y los autores como Viergol también oscilan en sus juicios. Se muestra poco partidario del academicismo, y a Ángel García le dice que huele a estatuaria de Canova. Detecta también similitudes o plagios; y resulta llamativa su denuncia de algunas obras como "robba di commercio". Simpático resulta su comentario sobre la escultura de Servetto Jesús ante el pueblo, donde plantea una suerte de performance: "Ahí tienen ustedes una escultura en colaboración con el público; el Sr. Servetto hizo a Jesús y nosotros hacemos de pueblo. Le pasaremos la cuenta por gastos de comparsa".

En la pintura, y con tan amplio número de piezas comentadas entre ambos catálogos es difícil plantear un mínimo resumen, ya que el autor abarca todo tipo de recursos. Entre ellos está la alusión a políticos de la época, como Navarro Reverter y su verbo florido o Canga-Argüelles con su puritanismo católico, más las conexiones con artistas antiguos o coetáneos; incluso inventa noticias periodísticas y propone letrillas para cantar con la melodía de determinadas canciones. Encontramos pasajes poéticos muy cuidados, aunque otros más breves son obvios y juegan con el nombre del autor o dan respuesta a los propios títulos ("Ese busto es de primera; choque usted, Sr. Parera"). También denuncia a menudo las alteraciones de escala: "El que la perspectiva va y desdeña/ creyéndola materia muy sencilla,/ se expone a hacer la estufa muy pequeña/ o archidescomunal la carretilla" (Emilio Alejandre, Plantas y flores). 0 bien cuestiona las gamas de color: Garí Torrent, Premio sin gozo: “¿Qué tendrá el color azul/ que abusan de él los pintores?.../ debe ser el más barato,/ no cabe duda, señores". Incluso parodia el propio contexto, cuanto ante el cuadro En Alcorcón de Mané, señala: "Esa tienda con tanto cacharro parece una alegoría de la Exposición de Bellas Artes".

En 1897 Viergol se hace eco de un refrán pictórico: "Cuadro bien colocado, amigo del

24 REYER0, Carlos, "Los orígenes de la escultura moderna y los críticos de las Exposiciones Nacionales", en $\mathrm{El}$ arte español del siglo XX. Su perspectiva al final del milenio, CSIC, Madrid, 2001, pp. 145-158.
Jurado", y es llamativa la alusión a Ciencia y caridad de un jovencísimo Pablo Ruiz Picasso (citado solo como Ruiz): "Siento ante tanto dolor/ reírme como un bergante,/ pero el caso es superior:/ ¿pues no está el señor doctor/ tomándole el pulso a un guante?”.

Aunque no podamos extendernos, esta edición de 1897 es quizás la mejor documentada. En parte porque disponemos de un completo catálogo comentado por el crítico Francisco Alcántara, que con todo lujo reproduce fotografías de las obras y permite cotejar gran número de reseñas. También por contar con publicaciones cómicas paralelas.

Así, bajo el seudónimo de El Diablo Cojuelo, se edita el mismo año la Revista cómica de la Exposición de Bellas Artes. Madrid 1897, un número único de 8 páginas, no secuenciado, con inserciones publicitarias en las dos últimas $^{25}$. Cuenta por tanto con financiación comercial, augurio de buenas perspectivas, que se cumplieron, pues el propio autor señala en un artículo paralelo que está en prensa una segunda edición ${ }^{26}$. Como reclamo ofrecía un precio muy módico (15 cts), alternativo a los dos reales que costaba el catálogo oficial, y la iniciativa se divulgó además en diversos medios de prensa $^{27}$.

Otra de sus particularidades es el formato de revista y su condición ilustrada, pues incluye caricaturas de 11 expositores, con autoría de Araña, y varias viñetas de situación firmadas por Polilla. Estas últimas recrean la presencia como observantes de críticos y público, ofreciendo valiosa información sobre el carácter social del acontecimiento. En una vemos el domingo a toda la familia, con 4 niños y perro; y en otra los saludos protocolarios en "los días de moda". (Fig.3)

Una vez más se concibe como guía para visitar la muestra, invitando a seguirla "siempre hacia la derecha", con los nombres de los artistas y títulos de las obras, aunque obviando su numeración, ya que no se rige por las indica-

25 Establecimiento Tipográfico de Idamor Moreno, Madrid, 1897. Disponible en la hemeroteca digital de la Biblioteca Nacional. http://hemerotecadigital.bne.es/ issue.vm?id=0026454399\&tsearch=\&tang=es.

${ }^{26}$ EL DIABLO COJUELO, "Solfa de la Exposición”, en Nuevo Mundo, no 178, 2 de junio de 1897, p. 16.

$27 \quad$ Así lo hacía en su apartado de noticias bibliográficas La Correspondencia de España, $\mathrm{n}^{\circ}$ 14.360, 31 de mayo de 1897 , p. 4, recomendando "un ameno y entretenido catálogo". 

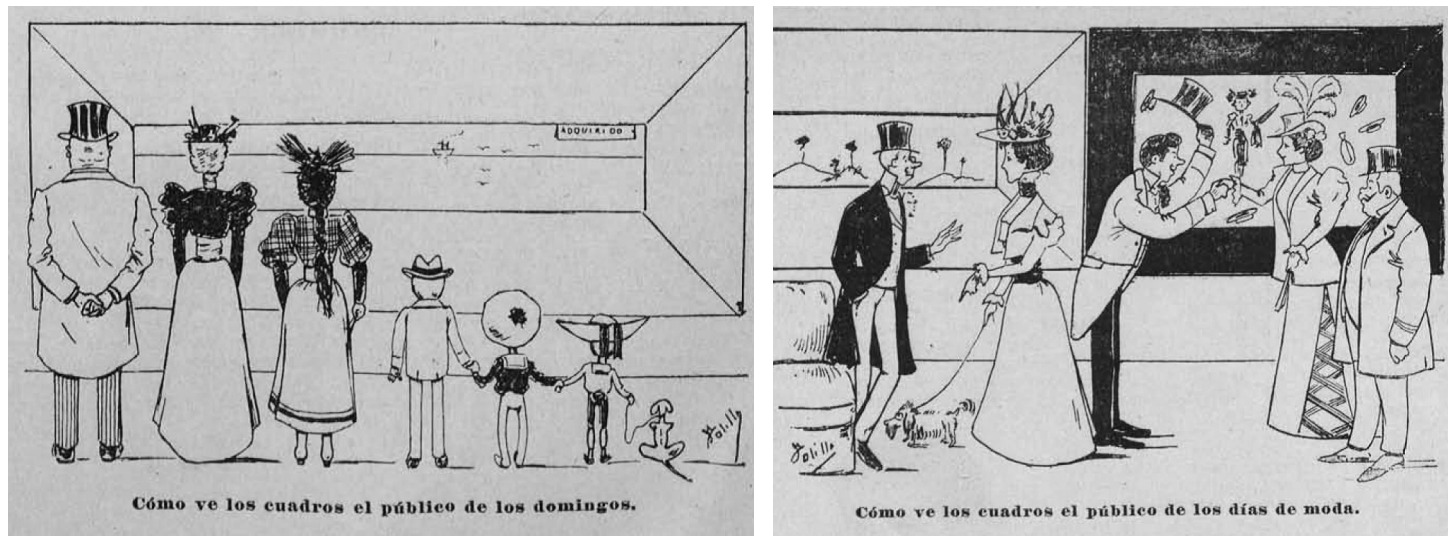

Fig. 3a y 3b. Dos viñetas de Polilla sobre la Exposición Nacional de 1897 en la Revista cómica realizada por El diablo Cojuelo.

ciones del catálogo oficial. Como novedad se permite modificar numerosos títulos a su antojo, haciendo juegos de palabras con la temática o el nombre del pintor. Nos encontramos pues ante una publicación más anárquica y libre de lo habitual, donde los cambios de título suponen un nuevo aliciente.

Con todo, al final de cada sala se citan sin burla algunas obras no comentadas, y se mantiene siempre un tono respetuoso. En la introducción aclara que sus bromas pretenden no hacer daño, "y que si a alguno falto, tenga presente/que él le faltó a mi vista primeramente".

Toca ya dar a conocer que, aunque firme en singular, detrás del citado seudónimo se encontraban en realidad los hermanos Serafín y Joaquín Álvarez Quintero ${ }^{28}$, comediógrafos andaluces de fecunda trayectoria, que en estas tempranas fechas se prodigaban también en crónicas de prensa. Su fama aporta también peso a estas iniciativas. Con su tono ligero habitual, saben apreciar los detalles y situaciones costumbristas, comentando ante el cuadro de Godoy Súplica fervorosa: "Por si Dios se lo concede,/ le pide con frases tiernas,/ que ya que todo lo puede/ le ponga iguales las piernas"; y ante Sola en el mundo: "Cabanzón, óigame usté,/ que le hablo con buenos modos:/ si los ha enterrado a todos, ¿cómo quiere usted que esté?".

Respecto a los cambios de título aplicados a los cuadros (Benedito: Uno que se siente bien, pero que se sienta mal), quizá las opciones más llamativas sean la crítica al puntillismo de Regoyos, rebautizándolo: Pintura a puñetazos; o el de Ramón Casas Moulín de la Galleta: “¿Se

28 Diccionario Biográfico Español, Real Academia de la Historia, Biografías, 7089. http://dbe.rah.es/biografias/7089/serafin-alvarez-quintero. titula de este modo? ¡Pues entenderlo es trabajo!.../ ¡Hombre! iQue pongan debajo/ una explicación de todo!”.

Finalmente, en 1899 tenemos la oportunidad de valorar un doble enfoque, por cuanto el número suelto que la revista Gedeón dedica a la Exposición Nacional ofrece tanto poemas como ilustraciones. Con 36 páginas de pequeño formato y un precio de 30 cts., esta manejable edición alterna comentarios sobre 185 pinturas y esculturas, con 25 dibujos sin firma que incluyen tintas de varios colores $^{29}$.

Por su excepcionalidad incidiremos más en los últimos, que parodian por ejemplo esculturas importantes. Se destaca así la elefantiasis del Velázquez de Aniceto Marinas (cuyo bronce se ubica ante el Museo del Prado); mientras La mina de carbón de Mateo Inurria se retitula en texto como Los estetas abriéndose camino y se transforma visualmente en El triunfo de la lavativa. (Fig. 4) Por su parte, el expresionismo de Carles Mani es abiertamente incomprendido al valorar su Instinto humano: "Ese torso, esa cabeza/ y esas piernas y esos brazos/ que a todo el mundo parecen/ hechas de hormigón hidráulico,/ ni muestran nada de instinto/ ni tienen nada de humano".

En el terreno pictórico encontramos también duras observaciones. Ante Mi primera obra de Ignacio Pinazo, el comentarista advierte: "No, joven, no; esa es anterior a la primera. La primera ya la hará usted cuando sepa”. Asistimos también a la conversión del cuadro de Conrado Sánchez Varona La obra de San Vicente de Paul en "Confiteras entregando unos zapatos de guirlache y huevos hilados a una familia de fenómenos".

\footnotetext{
29 Gedeón en la Exposición 1899, Imprenta de El Enano,
} Madrid, 1899 (32 páginas). 

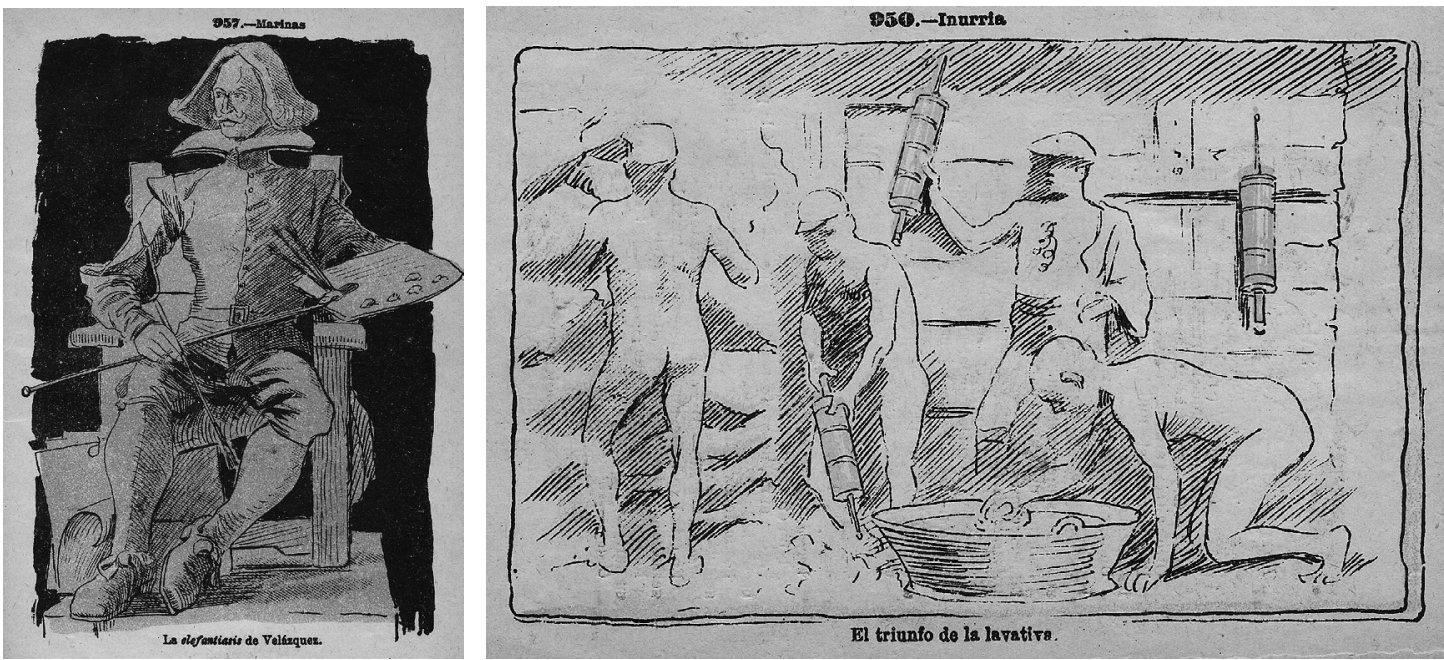

Fig. 4a y 4b. Gedeón. Parodias visuales de las esculturas Velázquez de Aniceto Marinas y La mina de carbón de Mateo Inurria. 1899.

Muy llamativas por último resultan las alusiones peyorativas a las técnicas impresionistas, de manera que respecto al Tendido de sombra de Darío de Regoyos señala: "La pincelada libre en el dibujo libre... ¡Me resulta mucha $l i$ brería!". Y el cuadro Natura de Eliseo Meifrén se identifica como Paisaje al ferroprusiato. Tampoco esta faceta de Sorolla sale bien parada: "Uno Cosiendo la vela.../ Otro, Comiendo en la barca.../ estos cuadros en gerundio,/ me hacen poquísima gracia./ El gachó de la derecha/ tiene por pies sobrasadas,/ y los hombres y los chicos,/ unas manos... y unas caras.../ iAy de mi Otra Margarita!/ ¡Ay de mi Trata de blancas!/ Aquellos sí que eran cuadros;/ éstos, don Joaquín, son manchas/ (en todas las acepciones/ peores de la palabra)". (Fig. 5)

En conclusión, estos catálogos humorísticos suponen una fuente alternativa para evaluar la percepción crítica del arte contemporáneo español. Se dirigen a un público medio, no nece- sariamente formado en materia artística, pero cuyo valor como espectador no es nada desdeñable. Hemos analizado el contexto y alcance de los mismos, con distintos niveles de preparación en los autores, vinculados más al ámbito literario que al plástico, pero con recursos y notas comunes que los caracterizan. Aun con sus limitaciones, estos catálogos ofrecen una perspectiva insólita y fresca sobre la manifestación expositiva más relevante de nuestro panorama artístico.

Y aquí acaba el recorrido,/con la sana pretensión/ de haber mostrado al versado/ versos a una Exposición./ Guías muy originales,/ redactadas con humor,/ que permiten al lector/ recorrer las Nacionales./ Un catálogo modélico,/ crítico a la par que irónico,/ debatiendo lo académico,/ lo icónico y lo polémico,/ con espíritu paródico./ Y junto con la pintura/ moderna y también casposa,/ un poquito de escultura/ valorada con mesura./ Terminamos, y a otra cosa.
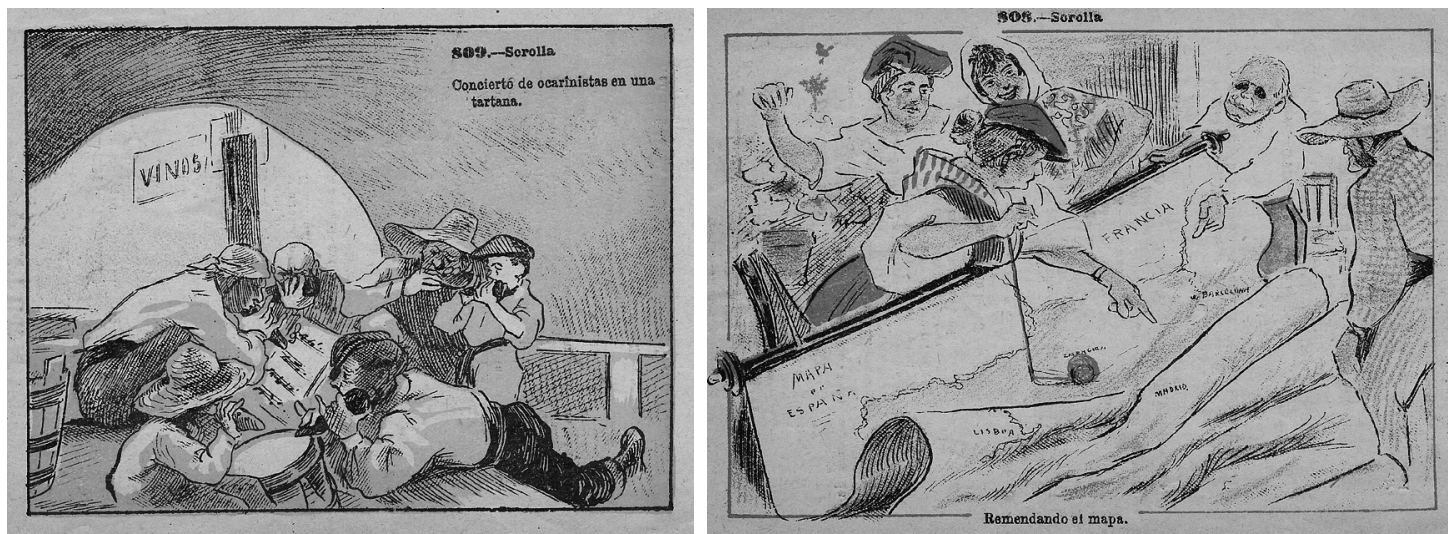

Fig. 5a y 5b. Gedeón en la Exposición de 1899. Parodias visuales de los cuadros de Sorolla Comiendo en la barca y Cosiendo las velas. 1899. 